\title{
Género epistolar y hermandad artística en la poesía de mujeres de la primera mitad del siglo $X X^{*}$
}

\author{
Lorena Garrido Donoso **
}

\begin{abstract}
Resumen
El siguiente artículo analiza la correspondencia de algunas poetas chilenas con Gabriela Mistral entre los años 1935 y 1954, época en que la escritura de mujeres comienza a profesionalizarse en Chile. Se sostiene que la base de la correspondencia entre las poetas obedece a una satisfacción de intenciones ligadas a crear un sentimiento de pertenencia, a ser parte de una red de escritoras como una estrategia para ser aceptadas dentro del canon literario masculino.
\end{abstract}

Palabras clave: género epistolar, Gabriela Mistral, redes, escritura de mujeres chilenas.

\section{Epistolary gender and artistic sisterhood in the poetry of women in the first half of the XX century}

\begin{abstract}
The following article analyzes the correspondence between Gabriela Mistral and other women poets during the years 1935-1954, a time when the writing by women starts to become a professional activity. It is said that the main reason for the writing of these letters is the satisfaction of needs related to the creation of a female subjectivity as well as building a female writers network as a strategy to be accepted within the masculine literary canon.
\end{abstract}

Key words: epistolary genre, Gabriela Mistral, networks, writing of Chilean women.

Recibido: 12-03-2013 Aceptado: 26-07-2013

\footnotetext{
* El siguiente trabajo es parte del Proyecto Fondecyt 1100754 titulado Tradición literaria y profesionalización en la escritura de mujeres, a cargo de Ana Traverso, y del cual la autora es coinvestigadora.

** Chilena, Doctora en Literatura, Universidad de Santiago de Chile, Santiago, Chile, lorenagarridod@ gmail.com
} 
Contrario a lo que por mucho tiempo se dijo de Gabriela Mistral, su éxito y reconocimiento no fueron fruto del destino, de la buena suerte ni de su difundido rol como maestra o madre universal. Tampoco fue únicamente el resultado de su incuestionable talento dentro de las letras hispanoamericanas, sino que se debe en gran parte, a las redes que desde muy al principio en su carrera poética se ocupó de formar. Lo anterior implica que Mistral tenía claro que el canon literario es masculino y patriarcal, lo que la lleva a desarrollar una serie de estrategias para ser considerada por sus pares, intentando desde el principio relacionarse con otros escritores latinoamericanos destacados, para luego, paralelamente, crear una "hermandad artística" con mujeres escritoras, poetas y artistas. El concepto, que explico a cabalidad en otro trabajo ${ }^{1}$, lo he desarrollado a partir del concepto de "hermandad lírica", una tradición de larga data entre las poetas, que ha sido expuesto por Iker González-Allende: "Ante la oposición de gran parte de la sociedad, las mujeres se apoyaban unas a otras (...) Así, se dedicaban poemas mutuamente, se escribían prólogos para sus libros y mantenían correspondencia aun sin conocerse" (43). La anterior es una característica que está presente en Gabriela Mistral, y que se observa claramente en sus dedicatorias así como en parte de su correspondencia; pero en su caso ella la extiende también a otras áreas del quehacer artístico e intelectual, al incluir en sus contactos a mujeres que desarrollan labores que superan el ámbito literario o poético, como escultoras, pintoras, pianistas. De ahí que en su caso me parezca más adecuado el término de "hermandad artística". El deseo de Mistral de crear esta hermandad obedece, como plantean Gilbert and Gubar (2000), a un intento desesperado de parte de la mujer artista por autodefinirse en un mundo patriarcal:

Thus the loneliness of the female artist, her feelings of alienation from male predecessors coupled with her need for sisterly precursors and successors, her urgent sense of her need for a female audience together with her fear of the antagonism of male readers, her culturally conditioned timidity about selfdramatization, her dread of the patriarchal authority of art, her anxiety about the impropriety of female invention- all these

1 A propósito, ver Garrido Donoso, Lorena, "No hay como una contadora para hacer contar": Mujer poeta en Gabriela Mistral. Santiago: Cuarto Propio, 2012. 
phenomena of "inferiorization" mark the woman writer's struggle for artistic self-definition and differentiate her efforts at self-creation from those of her male counterpart. (50)

Para Mistral la idea de sentirse parte de una tradición de mujeres es vital, si no en su primera etapa, en sus años posteriores. Por ello en la conferencia que da en Uruguay el año 1938, parte invocando a las ya partidas. Estas relaciones las crea mediante el único medio disponible en el momento: las cartas, que envía en grandes cantidades a distintas personalidades del ambiente literario y artístico de su tiempo.

El objetivo de este artículo es analizar la correspondencia que varias poetas y escritoras chilenas envían a Mistral en el período que va desde 1935 a 1954, época en que esta última ya gozaba de prestigio, el que se vería refrendado con el recibimiento del Nobel el año 1945. El ambiente literario femenino en Chile sufre también un cambio ya que es precisamente en esta época en que se profesionaliza la escritura de mujeres, lo que se refleja en una literatura muy prolífica, que también se extiende al género epistolar. Si consideramos que el género epistolar, pese a su especificidad, es un proceso interactivo de comunicación verbal y la idea de que siempre esta comunicación se hace a fin de expresar significados y satisfacer intenciones (Brown y Yule, 1983), cabe preguntarse: ¿Con qué intención escriben estas mujeres a Mistral? ¿Hay en ellas sólo amistad o también una conciencia de la necesidad de desarrollar redes para acceder al canon?

Considerando los aportes del análisis del discurso y la teoría de género, postulo que atendiendo a la "satisfacción de intenciones" es que se produce este intercambio epistolar, que tiene un sentido doble constituido por las intenciones de estas poetas y las de Mistral, manifestándose ambas partes a través de ciertas estrategias discursivas que les sirven para concretar estos propósitos. Dichas intenciones fluctúan dentro de una gama de intereses que van desde la reafirmación de la subjetividad de quien escribe a la búsqueda de apoyo dentro del ambiente literario y cultural de la época. Para ilustrar mi propuesta analizo la cartas²: escritas por Aída Moreno, Berta Lastarria, Chela Reyes,

2 La correspondencia analizada proviene en el caso de Mistral del libro Antología Mayor de Gabriela Mistral, Tomo III, 1992. Las cartas de las otras escritoras a Mistral fueron tomadas del archivo que está disponible en la Biblioteca Nacional en línea, proveniente en su mayoría de las pertenencias de Mistral donadas a dicha biblioteca por Doris Atkinson. 
María Flora Yáñez, Gabriela Huneeus, Vera Zouroff, Olga Acevedo, Iris, y María Donoso ${ }^{3}$, entre otras.

\section{El género epistolar y la escritura de mujeres}

Desde el punto de vista de la función, el género epistolar es "la comunicación diferida en el tiempo y entre espacios distintos, comunicación que se realiza mediante textos escritos" (Soto, 1996: 154). A esta distancia se refieren varios autores, como Oyanedel que lo llama "presencia ausente", superada esta ausencia por lo que Patrizia Violi (1987) ha llamado "diálogo diferido" y que, según la autora, se produce gracias a las características propias de la carta, idea que recoge Leonidas Morales (2001), quien explica: "la carta viene justamente a conjurar la ausencia, a intentar cubrir la distancia que separa a un yo de un tú, a un sujeto de otro, mediante un artificio discursivo que ante la imposibilidad del diálogo directo, real e inmediato, ofrece la alternativa de un diálogo diferido" (51).

Unida a esta condición de diálogo diferido, hay en la carta una permanente polaridad, lo que permite "the letter's flexibility and define its parameters, thus giving it recognizable dimensions of thematic emphasis and narrative potential" (Altman, 1982: 186). Este potencial narrativo ha estado históricamente ligado a la escritura de mujeres como medio de expresión, definición de su subjetividad y parte de su creación literaria, algo que ha llevado a algunos autores como Didier (1981) a

3 Aída Moreno (1896-1943), poeta y maestra, conoce a Gabriela Mistral en el liceo de Los Andes. Publicó un único libro de poemas titulado Dolidamente (1925).

Berta Lastarria (1883-1945), profesora y escritora, escribió fundamentalmente cuentos para niños, entre los que se destacan Lo que cuentan las hojas (1923), Lo que cuentan las nubes (1932).

Chela Reyes, su nombre verdadero fue Zulema Reyes. Se inició en la literatura en el año 1926, incursiona en el cuento, la novela y el teatro y el ensayo, pero se destacó sobre todo en poesía con los libros Poesías (1928) y Puertas verdes y caminos blancos (1939).

María Flora Yáñez (1898-1982), novelista, cuentista y ensayista. Publicó las novelas Mundo en sombras, Espejo sin imagen, Las cenizas, El estanque.

Gabriela Huneeus (1898-1958), poeta y escritora. Contribuyó con el diario “El Mercurio" y la revista "Zig-Zag". Su primer libro de poesía, publicado en 1944, se titula Voces en el tiempo. En 1954 publicó su segundo libro, Pradera Eterna.

Vera Zouroff, fue poeta, novelista, escultora y pintora. Fundó el periódico Mujeres de América y fue directora de la mesa Panamericana de mujeres. Se destacan sus novelas Martha (1916) y Liberación (1919). De Olga Acevedo (1875-1974) me refiero con más detalle en el cuerpo del artículo, pero es una poeta que comenzó a publicar en los años 20. Se destacan sus libros Cantos a la montaña (1927) y Donde crece el zafiro (1937).

Iris es el pseudónimo de Inés Echeverría (1869-1949), escritora, novelista, ensayista. Fue conocida por haber creado junto a otras mujeres el Club de Señoras, donde daba conferencias instando a la emancipación de la mujer. Entre sus obras destacadas se encuentran Hojas caídas (1910) y Entre deux mondes (1914).

María Donoso, hija de María Monvel y Armando Donoso, sobrina de la escritora Nina Donoso. 
considerar la carta como el "género femenino por excelencia" o como afirma De la Torre (2009): “El género epistolar ha permitido la expresión a diversas mujeres, convirtiéndose así en una tradición femenina y feminista" (74). Personalmente no me atrevería a afirmar que la escritura epistolar es necesariamente feminista ni femenina, pero es innegable que hay un nexo entre mujeres y género epistolar, dado, precisamente por esa polaridad que mencionaba con anterioridad y que permite un doble juego de mostrarse y esconderse a la vez: "depending on the writer's aim, the letter can be either portrait or mask" (Altman, 185). En ese juego de máscara/realidad es que las cartas se acercan a la literatura, es decir, hay una "literalidad en la carta" (Alfonso Reyes), la cual está aun más presente en el caso de las mujeres escritoras, ya que, como afirma Mercedes Arriaga (2005), las escritoras de profesión no abandonan su oficio de escritura cuando escriben sus cartas. Por último, concuerdo con Darcie Doll (2004) en que este rasgo fronterizo, polar de la misiva, es lo que "permite que la carta se constituya en un territorio excepcionalmente favorable de ser apropiado desde la marginalidad de las mujeres ante los discursos hegemónicos" (154).

Hay otro aspecto también importante relacionado con lo anterior, señalado por Mercedes Arriaga, y es que la carta es un instrumento que sirve a la mujer para ejercer contingencia y mediación y de esa manera satisfacer sus necesidades. En ese sentido, la carta permite por su estructura dirigir la comunicación por parte del emisor, valiéndose a menudo de la función metatextual, la "metacomunicación" en términos de Stubbs (1987). Estas interferencias metatextuales le permiten a la emisora de la carta volver sobre lo dicho y así destacar y contextualizar su discurso: "en este sentido, las indicaciones contextualizadoras (en un sentido lato del término) se incorporan de forma privilegiada al proceso de textualización epistolar y desempeñan en él una función comunicativa." (Soto, 157). 


\section{Mistral y la correspondencia}

Hay varios epistolarios de Gabriela Mistral que han sido publicados en forma total o parcial ${ }^{4}$, y se han hecho también varios estudios sobre esta correspondencia, particularmente sobre su escritura amorosa. Lo importante es destacar que la escritura de cartas era para Mistral parte de su oficio. Así sabemos por la gran cantidad de correspondencia encontrada y a juzgar por las fechas de éstas, que ella dedicaba varias horas al día a esta labor. La propia Mistral escribe sobre la importancia del género para ella en la nota a los Recados en Tala:

Las cartas que van para muy lejos y que se escriben cada tres o cinco años suelen aventar demasiado lo temporal -la semana, el año- y lo demasiado menudo -el natalicio, el año nuevo, el cambio de casa-. Y cuando, además, se las escribe sobre el rescoldo de una poesía, sintiendo todavía en el aire el revoloteo de un ritmo sólo a medias roto y algunas rimas de esas que llamé entremetidas, en tal caso, la carta se vuelve esta cosa juguetona, tira de aquí y allá por el verso y por la prosa que se la disputan. (163)

Como afirma Diamela Eltit (1990) "sus cartas se insertan como textos al interior de su obra" (49-50), hay una relación de esas cartas con su obra poética ya que como vemos ella misma veía a las cartas también como parte del juego creativo, como un subgénero entre prosa y poesía. A la vez Mistral relaciona esa correspondencia con su figura pública que ella construyó en parte a través de esas cartas; ella "utilizó las cartas para inscribir un fragmentario relato autobiográfico que hizo, deshizo, varió y confundió continuamente" (Salomone y Doll, 2006: 293). Es decir, Mistral se valió de su correspondencia para crear una imagen de ella, la imagen que quería que fuera percibida por los demás o que le servía para validar su posición frente a algunos temas. Así es como en muchas de sus cartas refiere a la pobreza en la que se encontraba siendo cónsul

4 Por dar algunos ejemplos tenemos la correspondencia amorosa con Manuel Magallanes Moure: Gabriela Mistral, cartas de amor y desamor, Santiago: Andrés Bello, 1999; su correspondencia con Victoria Ocampo: Esta América nuestra. Correspondencia 1926-1956. Introducción y notas de Elizabeth Horan y Doris Meyer. Buenos Aires: El cuenco de plata, 2007; El ojo atravesado: correspondencia entre Gabriela Mistral y los escritores uruguayos. Notas comentarios y edición de Silvia Guerra y Verónica Zondek, Santiago: Lom, 2005; Epistolario de Gabriela Mistral y Eduardo Barrios. Ed. Luis Vargas Saavedra, Santiago: Centro de Estudios de Literatura Chilena, 1988, y el último Niña Errante, Cartas a Doris Dana, Edición y prólogo de Pedro Pablo Zegers, Santiago: Lumen 2009, entre otros. 
en Europa, pidiendo a algunas personas que intercedieran por ella para recibir mejores condiciones económicas. También habla de sus distintas posturas políticas, personales y de paso niega el lesbianismo que ya por entonces comenzaban a achacarle ${ }^{5}$.

Paralelamente a esta función constituidora de subjetividad, Mistral utilizaba las cartas como medio para crear redes, algo que era bastante frecuente en la época, ya que una de las funciones fundamentales de la carta es que crea relaciones sociales y un efecto positivo en la identidad y el sentimiento de pertenencia, esto especialmente en el caso de las mujeres "who not infrequently played a marginal role in the household" (Borello, 2004: 107). Todas las escritoras del grupo que revisamos aquí no habían alcanzado el nivel de difusión y reconocimiento de Mistral. Algunas eran sus amigas personales, conocidas en alguna etapa previa de su vida como maestra y directora de liceos en distintas partes de Chile, como es el caso de Olga Acevedo.

\section{Redes en la poesía de mujeres chilenas}

Si bien la relación de Mistral con las poetas que le escriben es distinta en cada caso, hay de todas formas rasgos comunes que permiten analizar las cartas en bloque. Caso aparte es el de Olga Acevedo, con quien Mistral tuvo una relación más cercana y más extendida en el tiempo a juzgar por la cantidad de material encontrado al respecto.

De ese corpus se puede observar que casi todas las autoras comienzan utilizando lo que Soto denomina "relaciones intertextuales expresas", esto es, información en que se mencionan otras cartas y otras formas de comunicación previas que forman parte del contexto escrito. Muchas se refieren a cartas anteriores y a peticiones anteriores hechas por Mistral como su interés en ciertos libros o artículos, o en el caso de personas más cercanas, como Acevedo, cierta información sobre botánica que Mistral estaba buscando para hacer su Poema de Chile.

5 Dice Mistral en una de sus cartas: "Si hasta han colgado ese tonto lesbianismo, y que me hiere de un cauterio que no sé decir. ¿Han visto tamaña falsedad? , les dije. Lo único que faltaba, que dijeran esas barbaridades de esta pobre mujer. ¡Chismes! Todo eso es tan amargo, pero además ponzoñoso". Bendita mi lengua sea. Diario intimo de Gabriela Mistral. Editado por Jaime Quezada. Santiago: Planeta, 2002, 178. 
Ahora bien, esta contextualización lleva muchas veces el germen de la posterior captatio benevolentiae, entendida ésta como un tropos retórico "mediante el cual el autor busca concitar un acogimiento benévolo por parte del receptor" (Marchese y Forradellas, 50). Y esto es porque muchas veces dentro de la referencia intertextual va expresado el cumplimiento de algún favor solicitado por Mistral, como la enviada por la poeta Aída Moreno (fechada el 3 de junio de 1936), enviando los libros pedidos, o la de Vera Zouroff, diciéndole que le enviará números de la revista "Mujeres de América" que ella dirigía (6 octubre, 1949). Creo que este tipo de comentarios prepara o intenta crear un ambiente propicio para la petición que suele venir después del párrafo de captatio benevolentiae propiamente tal. Otro grupo de cartas remplaza el comentario del favor cumplido por una felicitación por algún premio o algún reconocimiento recibido por Mistral. Tal es el ejemplo que no proporcionan los siguientes fragmentos de cartas escritos en distintas etapas de la vida de Mistral:

El mejor momento que he pasado en estos melancólicos días otoñales, fue al encontrar en el diario su nombramiento de directora para el número 6. (Iris la felicita por ser nombrada Directora del Liceo de niñas $N^{\circ} 6$ )

No se puede usted imaginar con qué profunda alegría recibí la noticia de su premio Nobel, una mañana chilena, abriendo "La Nación" y alumbrada por este sol tan suyo, que la espera. (Chela Reyes la felicita por el Nobel, 5 de diciembre de 1945).

Deseo expresarle el inmenso contentamiento porque al fin, aunque $\mathrm{i}[\mathrm{g}]$ noblemente [sic] tarde Chile le otorga el merecido premio. Es doloroso que esta tierra de esperanzas y hermosísima de paisajes, tenga sin pudor hijos que desconocen la justicia y la verdad que se impone. Ud. es una de nuestras grandiosas montañas que se expresan con toda la hondura y la riqueza que posee el corazón de nuestra tierra y la digna y elevada estatura de sus cumbres. (Gabriela Huneeus la felicita por el Premio Nacional de Literatura, 18 de octubre de 1951).

Como vemos, todas estas felicitaciones presentan alusiones a la naturaleza. En las dos primeras se la relaciona con un estado de ánimo: "melancolía otoñal", o alegría al ser "alumbrada" por el sol chileno. La melancolía de la primera carta citada termina al saber de Mistral y en la segunda el sol acompaña a la noticia del Nobel. Lo anterior apoya la idea de que, efectivamente, hay en las cartas de estas mujeres mucho de literario, en el sentido también de crear un ambiente propicio para la 
lectura posterior. En la tercera carta, en cambio, se iguala a Mistral con uno de los elementos de la naturaleza, algo que la propia Mistral hacía en su poesía, en la que la hablante a menudo se comparaba con algún elemento natural. Este recurso es bastante frecuente en la escritura de mujeres que suelen ver en la naturaleza una similar situación de sometimiento y falta de valoración por parte del mundo mascultista (Cook, 2008: 4). Tanto en la carta de Iris como en la de Huneeus, vemos esta tristeza o sensación de injusticia que es propia de la captatio benevolentiae o como llama Campanini, "técnicas de autentificación" (2003: 197) que continúan y se desarrollan, usualmente en el segundo párrafo de estas cartas.

En el segundo párrafo la emisora suele hacer algún comentario de la situación del ambiente literario en Chile, por cierto siempre desfavorable, y mostrar que comparte con Mistral esa sensación de no pertenencia de la que ella siempre habló en sus cartas. El compartir esa posición de exclusión y discriminación del ambiente literario parece ser uno de los recursos más comunes de los que se valen estas poetas para lograr la simpatía de Gabriela Mistral. Tal es el caso de Aída Moreno criticando a Raúl Silva Castro (3 de junio de 1936): "pobre pigmeo que no tiene otra cosa que su fatuidad y su suerte para que lo soporten en El Mercurio". Mari Yan criticando a Arrieta en junio 1942: "Ha lanzado mezquinos juicios sobre mi obra", lo que ella asocia al hecho de ser mujer, y agrega que Arrieta tiene esa actitud hacia "toda mujer que triunfa o que empieza a triunfar".

Otras simplemente apelan a la preocupación por la persona de Mistral y su salud, dándole consejos o recomendaciones como la de Vera Zouroff (6 de octubre de 1949) que le recomienda raíces de frutillas para los ojos. O las de Acevedo que le cuenta de su Parkinson y que al ser más cercana a Mistral, a menudo agradece el envío del medicamento Parsidol desde Estados Unidos, hecho por Doris Dana. Y por supuesto, hay muchas que simplemente expresan abiertamente su admiración por Mistral, como la de Mari Yan (María Flora Yáñez, junio de 1942) que le dice que a pesar de haberla visto sólo una vez, la admira. A menudo este comentario de admiración va acompañado de una especie de reproche por la falta de noticias de Mistral, como la de Gabriela Huneeus (22 de diciembre de 1953), quien le escribe luego de años de no saber de ella: "Para mí, las verdaderas amistades voces del corazón y de selectas afinidades carecen de tiempo y de espacio. Por eso mi afecto y admiración hacia Ud. tiene segura eternidad. Claro que a veces aparece junto a este afecto la pena de estar posiblemente olvidada de sus sentimientos". 
Seguido de estos comentarios que buscan acogida favorable por parte de Mistral, y como en este último caso continuar el vínculo, viene el real propósito de las cartas, es decir, el mensaje central por parte de las poetas que las escriben, ya que en éste radica la necesidad que ellas buscan satisfacer. En todas las misivas, sin excepción, hay un favor que se le pide a Gabriela Mistral que suele ser en casi todos los casos, la petición de que la premio Nobel lea algún libro de la poeta que lo envía y lo comente, es decir, lo mismo que a su vez la joven Lucila Godoy intentó, exitosamente, con Rubén Darío. Veamos algunos ejemplos:

Le envío mi novela "Las cenizas", (...). Espero anhelante, Gabriela, su juicio sobre esta novela que cuenta la vida de una mujer y su soledad moral, que es acaso, la de toda alma femenina en nuestras tierras de Sud-América. (Mari Yan, en junio 1942)

Como vemos aquí se refuerza la petición de leer el libro apelando a la condición de minoría sometida de la mujer, algo que por sus escritos, a esas alturas ya se sabía que era una idea compartida por Mistral.

No he recibido contestación a mis cartas, y no me produce extrañeza, pero sí la tengo por su silencio respecto de mi libro "Voces en el tiempo", que le envié hace largos meses. (Gabriela Huneeus, 23 de mayo de 1945)

Hace algunos días, envié a usted mi último libro, 'Evocaciones del Perú', y lo dirigí al consulado de Chile en Los Angeles. Espero que el Cónsul se lo hará llegar a usted. (Vera Zouroff, 6 de octubre de 1949).

Muchas veces, estos favores se extendían a otros conocidos o incluso miembros de la familia como la que escribe Gabriela Huneeus el 26 de mayo de 1954: "Va adjunto un cuento de mi hija Gloria que puede gustarle: "Don Briceño". Es el brote de amor de su viejo jardinero que murió junto a ella, en su tierra en Parral. Historia auténtica. Ella es muy joven y tiene serias disposiciones artísticas. Ojalá las aproveche."

Otro es el caso de Berta Lastarria, quien en carta fechada en 1936, además de enviarle un libro, le envía las críticas que ha recibido de Clemente Palma y de paso le pide a Gabriela Mistral que corrija algo que dijo en una de sus reseñas en la que la pone al mismo nivel de Blanca Santa Cruz: "Si yo no tuviera por usted el prestigio y admiración que 
tengo, no habría rectificado su opinión, pero como está lejos, ha pasado a su lado ignorada mi modesta labor, y por esto le escribo, disculpándome por no haberle enviado mis libros, y pidiéndole un juicio sobre ellos". Si bien se recurre a un tono modesto, la petición no deja de ser bastante osada, considerando que corrige a Mistral en su "error"; ello indica de todas formas, la importancia del juicio de Mistral para la consagración de estas escritoras, especialmente cuando la crítica recibida por un hombre no ha sido positiva, tratando de revertir la situación con una crítica positiva de la única mujer que gozaba de autoridad para hacerla.

Además de estos "favores literarios", las peticiones son de diverso tipo, algunas bastante sorprendentes. Por supuesto, ello dependerá del grado de confianza y cercanía con Mistral. Así, Iris (Inés Echeverría), escritora ya conocida en la época y a quien Mistral contactó por su interés común en la teosofía ${ }^{6}$, le pide que le dé trabajo a una amiga como profesora. Esto es luego de felicitarla por haber sido nombrada directora del liceo n 6 de niñas. Ana María Núñez, en cambio, es la Presidenta de la Comisión directiva de la Biblioteca popular Gabriela Mistral en Mendoza y por ello le pide si le puede enviar algunas obras suyas (28 de abril de 1948). Amanda Labarca le escribe al consulado de California para pedirle participe en unos programas radiales como una de las 10 mujeres destacadas de Latinoamérica.

Olga Acevedo es la que suele pedirle otro tipo de favores más ligados al activismo, lo que es natural considerando que ella tuvo con Mistral una larga amistad, corroborada por años de correspondencia. De acuerdo a una carta de Acevedo a Mistral, fechada el 10 de marzo de 1949, sabemos que ambas se conocieron en Punta Arenas, cuando Mistral era directora del liceo de niñas de esa ciudad y Acevedo comenzaba su incursión en las letras. También la correspondencia entre ambas confirma el rol de "mentora" que Gabriela Mistral tendrá en la labor poética de Acevedo, la que solía enviarle sus libros en espera de su opinión. Tal como dice en la siguiente carta: “Yo le mandé mi último libro a California (...) le envío un nuevo ejemplar a Veracruz, porque me interesa que llegue a su poder y lo pueda hojear cuando tenga un minuto disponible"7. Mistral por su parte,

6 Así queda registrado en una carta fechada en 1915 en que Mistral dice a propósito de un artículo escrito por Iris sobre el tema: “Yo no pido respuesta para esta carta, yo necesito decirle lo que sigue nada más. Necesitamos una asociación de la índole de la que usted habló al reporter" (En La tierra tiene la actitud de una mujer, editado por Pedro Pablo Zegers, Santiago: Ril, 1999).

7 Carta fechada 10 de marzo de 1949, en archivos Biblioteca Nacional. 
escribe un artículo elogiando el libro de Acevedo de 1950, Las cábalas del sueño. La cercanía poética de ambas se debe no sólo a la admiración que Acevedo profesa a Mistral, sino que a las similitudes de sus puntos de vista sobre la literatura, la mujer que escribe y el ambiente literario chileno. Ambas comparten también un marcado interés social. Acevedo fue Vicepresidenta de la Alianza de Intelectuales y de la Sociedad de Escritores de Chile, agrupación que, como advierte Naín Nómez: “jugó un importante papel en los días de la Segunda Guerra Mundial, cuando los escritores se sumaron a la campaña antinazi" (133). Recordemos que Mistral también hizo mucho por los escritores europeos que fueron detenidos o estaban en peligro de serlo. Esta cercanía hace que Acevedo le pida desde remedios para el Parkinson hasta que interceda por otros escritores o agrupaciones perseguidas, como la que escribe en marzo de 1956 agradeciéndole acoger su petición de ayudar a los bolivianos que viven en dictadura. En otra fechada el 15 de enero de 1952 le cuenta de las gestiones para traer a Neruda de vuelta a Chile.

Pero sin duda la petición más extraña es la que hace María Donoso. Donoso era la hija de María Monvel y Armando Donoso, ambos grandes amigos de Mistral, quien apoya a Monvel desde el comienzo de su carrera. En el artículo de 1935 titulado "Elogio de María Monvel", Mistral la pone a la par de las otras grandes poetas latinoamericanas del momento, Storni e Ibarbourou ${ }^{8}$. Ambas mantienen una correspondencia que dura años, ya que Mistral le escribe a ella y a su marido, el crítico y sub-director del diario El Mercurio en ese entonces, Armando Donoso. Este apoyo y amistad va a sufrir un gran quiebre en 1935 por la filtración de una carta de carácter privado que Mistral le envía al matrimonio y que le valió su traslado de España a Portugal. Sin embargo, hubo al parecer una reconciliación con dicho matrimonio, a juzgar por los comentarios de María Donoso a Mistral. En una primera carta fechada el 18 de febrero de 1947, Donoso le agradece una carta que Mistral publicó para ella con motivo de la muerte de su padre. Pero luego en otra carta fechada el 14 de mayo de 1952, Donoso le pide abiertamente que se haga cargo de ella: "lléveme a su lado, Gabriela".

8 “La mejor poetisa de Chile, pero más que eso: una de las grandes poetisas de nuestra América, próxima a Alfonsina Storni por la riqueza del temperamento, a Juana por la espontaneidad. Empecé por admirarla y he acabado por quererla" (239). Este mismo texto utilizará Monvel para referirse a sí misma en su antología Poetisas de América (1930). 
De modo que las peticiones a Mistral son de todo tipo, y van a variar de acuerdo al período de la carrera de Mistral y por ende, al grado de poder que ella tenía, así como al grado de cercanía que tenía la emisora de la carta con la poeta de Elqui. El propósito es mayoritariamente encontrar ayuda y apoyo para poder hacerse de un lugar dentro de la carrera literaria, esperando que Mistral al leer sus libros pueda comentarlos, tal vez escribir un artículo sobre ellos y ayudar así a su difusión.

Pero ¿qué ganaba Mistral con esta correspondencia con poetas chilenas cuando ella ya no estaba aquí y tenía un lugar consagrado dentro de la literatura hispanoamericana? ¿Cuál era su propósito o necesidad resuelta a través de esta correspondencia?

Los propósitos de Mistral parecen ser variados. Por una parte, el mantener contacto con otras poetas chilenas le permite crear redes de lealtad, algo que ella consideraba importante, más aún entre las mujeres, en las que ella veía lucha permanente y poca solidaridad de género, esto unido al rechazo que ella siempre sintió recibir desde su país ${ }^{9}$. Por otra parte, en Mistral siempre hubo un interés por el intercambio literario con otros escritores, algo que Elizabeth Horan y Doris Meyer advierten sobre su correspondencia con Victoria Ocampo: "para ambas mujeres, escribir cartas las llevaba necesariamente al contexto de los libros y la lectura [...] la insistencia mutua en compartir la pasión por la literatura a través de las cartas fue también un acto de amor" (27). Este interés de Mistral por compartir literatura se observa no sólo en las peticiones que hace de libros de autores chilenos y recomendaciones de cuáles leer que le hace a sus destinatarias, sino también, como mencioné antes, en casi todas las cartas de otras poetas se menciona el envío de libros o artículos solicitados por Mistral. Al parecer, y como es lógico, mientras mayor cercanía, más envío de libros. Por eso en el caso de Olga Acevedo, de quien encontramos mayor número de cartas (veinte), hay en cada una mención a títulos o envío de literatura chilena, que esta última consideraba recomendable. Por otra parte, la idea de Mistral de escribir un libro sobre flora y fauna chilena (que luego se constituiría en el Poema de Chile), al parecer era conocido por mucha gente, ya que varias

9 Ejemplos de la opinión adversa que Mistral dice se tiene de ella en Chile, hay muchos. Veamos uno de muestra: "cosas muy malas han dicho de mí en aquel país que Dios me dio por patria. A ciertos compatriotas sólo les falta atribuirme un asesinato" (En Bendita mi lengua sea, 195). 
mencionan el envío de recortes sobre esos temas. Es interesante observar que si bien la interacción verbal es unilateral en la carta (Van Dijk, 1978: 240) y más aún, en este caso en que no analizo las cartas de Mistral, queda claro que el propósito de ambas partes crea una relación de intercambio y retroalimentación a las necesidades respectivas. Esto es, mientras Mistral busca información sobre el estado de la literatura en Chile y sobre temas específicos, sus interlocutoras utilizan esta necesidad como una manera de captar la atención de Mistral (captatio benevolentiae), iniciando la interacción, muchas veces hablando de esos envíos o usándolos como antesala a la petición que quieren hacerle. Pero además de saber sobre literatura, hay en Mistral también un interés en saber sobre lo que ocurre en el ambiente literario y aunque varias poetas le cuentan sus problemas con alguno de los críticos de la época, las más cercanas a ella como las poetas Chela Reyes y Olga Acevedo le cuentan con más detalle eventos que se acercan más bien al chisme del ambiente literario y cultural de Chile en ese momento. Acevedo parece gozar de gran confianza de parte de Mistral no sólo por sus peticiones, sino por el hecho de que le hace muchos trámites y actúa como intermediaria de muchos mensajes de Mistral a otros escritores. Por ejemplo, en carta fechada el 14 de junio de 1950, luego de darle cuenta del envío de catálogos de libros de botánica y zoología, le habla de la pelea por el premio nacional; luego le da cuenta pormenorizada del escándalo del Premio Municipal de Poesía. Le comenta además sobre las discusiones en la Sociedad de Escritores de Chile a la que llama "nido de víboras" y para terminar, le habla de la posible candidatura de Ibáñez. Luego en una carta posterior del 15 de enero de 1942, la felicita por estar lejos: “Consoladores recuerdos. Con ellos vivo, ya que no hay otra mejor alegría en este pequeño mundillo de peleas políticas y batallas intelectuales de aldea pobre." Acevedo también le habla de diversos problemas en el ambiente literario, utilizando su influencia sobre Mistral para verter opiniones sobre algunas escritoras a las que no considera importantes. Por otra parte, se encarga de reforzar el círculo de artistas e intelectuales que ya en esa época son amigos de Mistral y en algunas cartas incluso le envía las firmas de algunos de ellos con los que ha estado departiendo. De modo que Mistral puede así hablar de literatura, reforzar un círculo de lealtad que considera necesario para la protección de su imagen y mantenerse informada de los asuntos del ambiente literario y político chileno a través de personas que la aprecian y que también mucho le deben. 


\section{Conclusiones}

En síntesis, Mistral no sólo basó su estrategia de inserción y reconocimiento a través de su contacto con otros escritores canónicos, particularmente en sus comienzos, sino que paralelamente intentó crear una tradición de mujeres, buscando solidaridad en otras que como ella se atrevían a escribir y hacer de ello un oficio en Latinoamérica y en el resto del mundo. De esta manera pudo hacerse de un lugar dentro del ambiente literario y cultural de su tiempo, a la vez que le sirvió para difundir la imagen que quería que se tuviera de ella, destacando los rasgos que quería se asociaran a su imagen y dando su opinión sobre distintos asuntos políticos, culturales y literarios.

Así también dio apoyo a las más jóvenes, sobre todo en Chile, dándoles ánimos, comentando sus libros, usando su influencia para hacer difundir la obra de otras. Ellas por su parte, aprovecharon la influencia de Mistral para hacerse conocidas, poder contactarse con otros escritores a través de ella y recibir una crítica o comentario de la premio Nobel que les sirviera para mejorar su escritura. En este juego doble de búsqueda de satisfacer intenciones y por otra parte de crear una subjetividad que le permita validarse frente al otro y a la vez dentro del ambiente literario e intelectual, es lo que subyace en la escritura epistolar de estas mujeres. Todo ello expresado a través de distintas estrategias de captación de atención, de búsqueda de simpatía que les da la sensación de no pertenencia en un mundo patriarcal, tal como alguna vez lo hiciera la joven Lucila con Rubén Darío:

Yo, Rubén, soi una desconocida; yo no publico sino desde hace dos meses (...), yo, maestra, nunca pensé antes hacer estas cosas que Ud., el mago de la Niña-Rosa, me ha tentado y empujado a que haga. ¡Es Ud. culpable de tantas cosas en el campo juvenil! ¡Si supiera, si supiera! (Antología mayor 57) 


\section{Referencias}

Altman, Janet Gurkin (1982). Epistolarity: approaches to a form. Ohio State University Press.

Arriaga Flórez, Mercedes (2005). “Epistolarios en Italia: un Punto de Vista Teórico Sobre un Género Femenino". Epistola I Literatura: Epistolaris, la Carta: Estratègies Literàries. Alicante, España. Denes. Vol. 1. 69-78.

Borello, Benendetta (2004). “Family networking. Purpose and form of epistolary conversation between aristocratic siblings. (Siena 17th century)". Reading, interpreting and historicizing: Letter as historical sources. Schulte, Regina y Von Tippleskirch, Xenia (editoras). San Domenico: European University Institute, 107-122.

Brown, Gillian y George Yule (1983). Discourse analysis. Cambridge: Cambridge University Press.

Campanini Catani, Magda (2003). “La scrittura epistolare fra realta e romanzo: les 'Lettres amourouses des divers autheurs de ce temps", en Rivista di letterature moderne e compárate 56 (junio). 441-456.

Cook, Barbara J. (2008). "Introduction: nature writing from the feminine". Women writing nature: a feminist view. United States: Lexington books, 1-6.

De la Torre Lozano, Dora (2009). “Género epistolar y didáctica en Sor Juana, tradición femenina y feminista". Revista electrónica Ideas Concyteg 44, año 4. 73-83.

Didier, B. (1981). L' Ecriture-femme, París: Presses Universitaires Francaises.

Doll, Darcie (2004). "Las cartas de amor de Gabriela Mistral o el discurso amoroso en las cartas de Gabriela Mistral". Modernidad en otro tono: escritura de mujeres latinoamericanas, 1920-1950. Alicia Salomone, Gilda Luongo et al., Santiago de Chile: Editorial Cuarto Propio. 
Eltit, Diamela (1990). "Personaje en correspondencia". Una palabra cómplice. Encuentro con Gabriela Mistral. Raquel Olea y Soledad Fariña (editoras). Santiago: Cuarto Propio.

Garrido Donoso, Lorena (2012). "No hay como una contadora para hacer contar": Mujer poeta en Gabriela Mistral. Santiago: Cuarto Propio.

Gilbert and Gubar (1979). The Madwoman in the Attic. The Woman Writer and the Nineteenth-Century Literary Imagination. New Haven: Yale University Press.

González Allende, Iker (2004). "Entre la modestia y el orgullo: las coordenadas metapoéticas de Carolina Coronado". Decimonónica 1.33-51.

Ludmer, Josefina (1984). “Tretas del débil”, en Ortega, Eliana y González, Patricia E., La sartén por el mango. Encuentro de escritoras latinoamericanas, Huracán, Río Piedra.

Marchese, Angelo y Forradellas, Joaquín (1997). Diccionario de retórica, crítica y terminología literaria. Barcelona: Ariel.

Mistral, Gabriela (1992). Antología Mayor. Santiago: Cochrane. Tomo III, Cartas.

. (1946). Tala. Buenos Aires: Losada.

. (2007). Esta América nuestra. Correspondencia 1926-1956. Introducción y notas de Elizabeth Horan y Doris Meyer. Buenos Aires: El cuenco de plata.

. (2002). Bendita mi lengua sea: diario intimo de Gabriela Mistral. Compilación y prólogo de Jaime Quezada. Santiago: Planeta.

. (1999). La tierra tiene la actitud de una mujer. Selección y prólogo de Pedro Pablo Zegers, Santiago: RIL.

Monvel, María (1929). Poetisas de América. Santiago: Nascimento.

Morales, Leonidas (2001). La escritura de al lado. Géneros referenciales. Santiago: Cuarto Propio. 
Nómez, Naín (2000). Antología Crítica de la poesía chilena. Santiago: LOM, Tomo II.

Oyanedel, Marcela (1985). La parole envoyée. Analyse sintanxique dún corpus écrit dé espagnol du Chili. Université Paris VRené Descartes, Sciences Humaines-Sorbonne. Tesis de Doctorado.

Reyes Alfonso (S/A). Literatura epistolar. Varios autores. España, Océano.

Soto, Guillermo (1996). “La creación del contexto: función y estructura en el género epistolar". Onomazein 1. 152-166.

Salomone, Alicia y Doll, Darcie (2006). “La literatura menor de Gabriela Mistral y Victoria Ocampo: la prosa epistolar y las alianzas", en Márgara Russotto (editora), La ansiedad autorial. Formación de la autoría femenina en América Latina: los textos autobiográficos, Editorial Equinoccio - Universidad Simón Bolívar, Caracas. 291-306.

Stubbs, Michael (1987). Análisis del discurso. Análisis sociolingüístico del lenguaje natural. Madrid: Alianza.

Van Dijk, Teun (1978). La ciencia del texto. Un enfoque interdisciplinario. Barcelona, Paidós.

Violi, Patrizia (1987). "La intimidad de la ausencia: Formas de la escritura epistolar". Revista de Occidente 68 (enero). 87-99. 